\title{
Biochemical and molecular characterization of Alternaria alternata isolates highly resistant to procymidone from broccoli and cabbage
}

Bingran Wang ${ }^{1}$, Tiancheng Lou', Lingling Wei', Wenchan Chen' Longbing Huang ${ }^{2}$, Lei Ding ${ }^{3}$, Weicheng Zhao ${ }^{1}$, Pengcheng Zhang ${ }^{1}$, Patrick Sun ${ }^{1}$, Changjun Chen $^{1^{*}}$ (D) and Kai Wang ${ }^{4^{*}}$

\begin{abstract}
Alternaria alternata, a causal agent of leaf blights and spots on a wide range of hosts, has a high risk of developing resistance to fungicides. Procymidone, a dicarboximide fungicide (DCF), has been widely used in controlling Alternaria leaf blights in China for decades. However, the resistance of A. alternata against DCFs has rarely been reported from crucifer plants. A total of 198 A. alternata isolates were collected from commercial fields of broccoli and cabbage during 2018-2019, and their sensitivities to procymidone were determined. Biochemical and molecular characteristics were subsequently compared between the high-level procymidone-resistant (Pro ${ }^{H R}$ ) and procymidone-sensitive $\left(\mathrm{Pro}^{\mathrm{S}}\right.$ ) isolates, and also between Pro ${ }^{H R}$ isolates from broccoli and cabbage. Compared with Pro $^{\mathrm{S}}$ isolates, the mycelial growth rate, sporulation capacity and virulence of most Pro ${ }^{\mathrm{HR}}$ isolates were reduced; Pro $^{\text {HR }}$ isolates displayed an increased sensitivity to osmotic stresses and a reduced sensitivity to sodium dodecyl sulfate (SDS); all Pro ${ }^{\mathrm{HR}}$ isolates showed a reduced sensitivity to hydrogen peroxide $\left(\mathrm{H}_{2} \mathrm{O}_{2}\right)$ except for the isolate B102. Correlation analysis revealed a positive cross-resistance between procymidone and iprodione, or fludioxonil. When treated with $10 \mu \mathrm{g} / \mathrm{mL}$ of procymidone, both mycelial intracellular glycerol accumulations (MIGAs) and relative expression of $\mathrm{AaHK1}$ in $\mathrm{Pro}^{\mathrm{S}}$ isolates were higher than those in Pro ${ }^{\mathrm{HR}}$ isolates. Sequence alignment of AaHK1 from ten Pro ${ }^{H R}$ isolates demonstrated that five of them possessed a single-point mutation (P94A, V612L, E708K or Q924STOP), and four isolates had an insertion or a deletion in their coding regions. No significant difference in biochemical characteristics was observed among Pro ${ }^{\mathrm{HR}}$ isolates from two different hosts, though mutations in AaHK1 of the cabbage-originated Pro ${ }^{\mathrm{HR}}$ isolates were distinct from those of the broccoli-originated Pro ${ }^{\mathrm{HR}}$ isolates.
\end{abstract}

Keywords: Alternaria alternata, Broccoli, Cabbage, Resistance, Dicarboximide fungicides, Fitness, AaHK1

\section{Background}

A leaf spot and blight disease, caused by the filamentous fungus Alternaria alternata (abbreviated as ALSB), is among the most common diseases of numerous economic crops, including crucifers (such as cabbage,

\footnotetext{
*Correspondence: changjun-chen@njau.edu.cn; 13851051048@163.com 'College of Plant Protection, Nanjing Agricultural University, Key Laboratory of Pesticide, Nanjing 210095, Jiangsu Province, China

${ }^{4}$ Jiangsu Coastal Area Institute of Agricultural Sciences, Yancheng 224002, Jiangsu Province, China

Full list of author information is available at the end of the article
}

cauliflower and broccoli), bean, cotton, citrus and tomato (Nowicki et al. 2012; Mukesh et al. 2016). The pathogen can infect a wide range of hosts and produce mycotoxins, posing a severe threat to safe food and vegetables worldwide, for instance, the reduced quality of cauliflower heads and brassicaceae oil (Guillemette et al. 2004; Surviliene \& Dambrauskiene 2006; Meena \& Samal 2019). Owing to few commercially-satisfactory ALSB-resistant varieties of brassicaceae vegetables available, chemical control is relied to control ALSB in the

(c) The Author(s). 2021 Open Access This article is licensed under a Creative Commons Attribution 4.0 International License, which permits use, sharing, adaptation, distribution and reproduction in any medium or format, as long as you give appropriate credit to the original author(s) and the source, provide a link to the Creative Commons licence, and indicate if changes were made. The images or other third party material in this article are included in the article's Creative Commons licence, unless indicated otherwise in a credit line to the material. If material is not included in the article's Creative Commons licence and your intended use is not permitted by statutory regulation or exceeds the permitted use, you will need to obtain permission directly from the copyright holder. To view a copy of this licence, visit http://creativecommons.org/licenses/by/4.0/. 
field. Currently, dicarboximide fungicides (DCFs) (Dry et al. 2004), quinol-oxidizing inhibitors (QoIs) (Ma et al. 2003), succinate dehydrogenase inhibitors (SDHIs) (Avenot \& Michailides 2007) and sterol demethylation inhibitors (DMIs) (Avenot et al. 2016) are intensively used to control ALSB.

The DCFs, including procymidone and iprodione, have been registered to control ALSB of cabbage and broccoli for decades in China (Ma \& Michailides 2004). The biochemical mechanism of DCFs against phytopathogenic fungi is documented to regulate high osmolarity glycerol (HOG) MAP kinases, interfering with the phosphorylation of transduction-associated proteins and glycerol biosynthesis (Cui et al. 2002; Lin \& Chung 2010). DCFs and phenylpyrroles are reported to target the same enzyme, a fungal two-component histidine kinase (HK), which belongs to group III hybrid histidine kinases involved in an osmotic-regulatory signal transduction cascade of mitogen-activated protein kinase (MAPK) signaling pathway, i.e., HOG-MAPK (Avenot et al. 2005; Lin \& Chung 2010; Ren et al. 2016). This cascade not only perceives extracellular stimuli, but also maintains intracellular osmotic homeostasis. Positive crossresistance between DCFs and phenylpyrroles is frequently observed in phytopathogenic fungi highly resistant to fludioxonil, including Botrytis cinerea (Sang et al. 2018), Bipolaris maydis (Han et al. 2017), Stemphylium solani (Wu et al. 2015) and Sclerotinia sclerotiorum (Duan et al. 2013). The typical structure of fungal group III HKs from major phytopathogenic fungi is composed of three domains: Histidine kinases-Adenylate cyclasesMethyl accepting proteins and Phosphatases (HAMPs, functionally named as "sensor domain") at a highly variable N-terminus, a central transmitter domain composed of histidine kinase A (HisKA) and cognate histidine kinase-like ATPase catalytic subdomains (HATPase_c), and a C-terminus receiver domain harboring a three amino-acid signature (DDK) (Herivaux et al. 2016).

Due to the extensive application of DCFs, the resistance against this type of fungicides has been reported in several phytopathogenic fungi, including Alternaria spp. (Dry et al. 2004; Avenot et al. 2005; Luo et al. 2008, 2012), Sclerotinia spp. (Ma et al. 2009; Kuang et al. 2011; Duan et al. 2013), B. cinerea (Fraile et al. 1986; Oshima et al. 2002; Cui et al. 2004; Grabke et al. 2014), Magnaporthe grisea (Motoyama et al. 2005), Stemphylium vesicarium (Alberoni et al. 2010), Neurospora crassa (Fujimura et al. 2000; Miller et al. 2002; Ochiai et al. 2010) and Cochliobolus heterostrophus (Yoshimi et al. 2003, 2004). The molecular mechanisms of DCFresistance include amino acid substitution in group III HK proteins, deletion or insertion mutations in their coding regions (Cui et al. 2004; Dry et al. 2004; Luo et al. 2008). Mutations in AaHK1 (insertion or deletion) of A. alternata lead to premature termination of the AaHK protein (Dry et al. 2004). Similarly, diverse mutations are found in AbNIK1 of Alternaria brassicicola, including nonsense mutations, a frameshift and a single amino acid substitution (E753K) (Avenot et al. 2005), while deletions and single amino acid substitutions are detected in AlHK1 of Alternaria longipes (Luo et al. 2008, 2012). In brief, it is intriguing to observe a high degree of diversity among mutations in HKs of the DCF-resistant isolates from Alternaria spp..

The mutations of HK1s are involved in the development of resistance to DCFs in fungal pathogens under certain selective pressure (Dry et al. 2004). Recently, growers has raised concerns about the decreased efficacy of DCFs against ALSB on cabbage and broccoli in Jiangsu Province of China. The objectives of this study were to (i) investigate whether procymidoneresistant $\left(\mathrm{Pro}^{\mathrm{R}}\right)$ populations of $A$. alternata has developed in commercial fields of cabbage and broccoli that were repetitively exposed to procymidone; (ii) compare biochemical characteristics between $\mathrm{Pro}^{\mathrm{S}}$ and Pro $^{\mathrm{HR}}$ isolates, and also between Pro ${ }^{\mathrm{HR}}$ isolates from broccoli and cabbage; (iii) reveal possible molecular resistant mechanisms of $A$. alternata against procymidone.

\section{Results}

Frequencies of resistance against procymidone in natural populations of $A$. alternata from broccoli and cabbage

The 198 isolates of A. alternata were obtained during 2018-2019, including 114 isolates from broccoli and 84 isolates from cabbage in Yancheng City, Jiangsu Province, China. Of the 114 isolates from broccoli, 7 highlevel procymidone-resistant $\left(\mathrm{Pro}^{\mathrm{HR}}\right)$ isolates and 60 lowlevel procymidone-resistant $\left(\mathrm{Pro}^{\mathrm{LR}}\right)$ isolates were detected with resistance frequencies of 6.14 and 52.63\%, respectively (Table 1). Of the 84 isolates from cabbage, in contrast, $3 \mathrm{Pro}^{\mathrm{HR}}$ isolates and $45 \mathrm{Pro}^{\mathrm{LR}}$ isolates were found with resistance frequencies of 3.57 and $53.57 \%$, respectively (Table 1). The data indicate that DCFresistant populations of $A$. alternata has developed in commercial fields of broccoli and cabbage.

The $\mathrm{EC}_{50}$ values of all $\mathrm{Pro}^{\mathrm{HR}}$ isolates from broccoli and cabbage were more than $100 \mu \mathrm{g} / \mathrm{mL}$, while the values for Pro ${ }^{\mathrm{S}}$ isolates were less than $1 \mu \mathrm{g} / \mathrm{mL}$ (Table 2).

Fourteen representative single-spore isolates, including ten $\mathrm{Pro}^{\mathrm{HR}}$ isolates $(\mathrm{C} 5, \mathrm{C} 13, \mathrm{C} 40, \mathrm{~B} 30, \mathrm{~B} 35, \mathrm{~B} 46, \mathrm{~B} 53$, $\mathrm{B} 88, \mathrm{~B} 102$ and $\mathrm{B} 108)$ and four $\mathrm{Pro}^{\mathrm{S}}$ isolates $(\mathrm{C} 10$ and C28 from cabbage; B16 and B21 from broccoli), were selected for phylogenetic analyses base on ITS and KOG1058 sequences (Fig. 1) and for further experiments. 
Table 1 Sensitivities of Alternaria alternata isolates to procymidone from Yancheng City, Jiangsu Province, China during 2018-2019

\begin{tabular}{|c|c|c|c|c|c|c|c|}
\hline \multirow[t]{2}{*}{ Location $^{a}$} & \multirow[t]{2}{*}{ Host } & \multirow[t]{2}{*}{ Total $^{b}$} & \multicolumn{3}{|c|}{ Number of isolates } & \multicolumn{2}{|c|}{ Frequency of resistance $(\%$} \\
\hline & & & $\mathrm{S}$ & LR & HR & LR & HR \\
\hline Xiangshui, JS & Broccoli & 114 & 47 & 60 & 7 & 52.63 & 6.14 \\
\hline Xiangshui, JS & Cabbage & 84 & 36 & 45 & 3 & 53.57 & 3.57 \\
\hline
\end{tabular}

${ }^{a}$ The samples were collected from Yancheng City, Jiangsu Province (JS), China. ${ }^{\mathrm{b}}$ The number of total isolates. S, procymidone-sensitive isolates, LR, low-level procymidone-resistant isolates, HR, high-level procymidone-resistant isolates

\section{Cross-resistance}

All the Pro ${ }^{\mathrm{HR}}$ isolates from broccoli and cabbage were also highly resistant to fludioxonil and iprodione based on their $\mathrm{EC}_{50}$ values (Table 2). The Spearman's rank correlation coefficient between the sensitivity against procymidone and fludioxonil, or iprodione was 0.9870 or 0.9824 $(P<0.001)$, respectively, suggesting a positive correlation (a positive cross-resistance) between procymidone and fludioxonil or iprodione was present in these tested $A$. alternata isolates.

\section{Mycelial growth, sporulation and virulence in $\mathrm{Pro}^{\mathrm{HR}}$ and}

\section{Pro ${ }^{\mathrm{S}}$ isolates of $A$. alternata}

The mycelial growth rates of the Pro ${ }^{\mathrm{HR}}$ isolates on fungicide-free potato dextrose agar medium (PDA) were significantly reduced compared with those of the Pro ${ }^{\mathrm{S}}$ isolates $(P=0.05)$ (Table 3). No significant difference in mycelial growth was observed among the Pro ${ }^{\mathrm{HR}}$ isolates from cabbage and broccoli (Table 3). Compared with $\mathrm{Pro}^{\mathrm{S}}$ isolates, the sporulation capacity of the Pro ${ }^{\mathrm{HR}}$ isolates (except for isolates B46 and B88) was significantly reduced $(P=0.05)$ (Table 3$)$. Furthermore, the virulence of the Pro ${ }^{\mathrm{HR}}$ isolates (except for isolates B35 and B53) on broccoli detached leaves was also significantly weakened compared with that of the $\operatorname{Pro}^{\mathrm{S}}$ isolates $(P=$ 0.05) (Fig. 2 and Table 3). Intriguingly, all Pro ${ }^{\mathrm{HR}}$ isolates from cabbage and broccoli fluctuated markedly in sporulation capacity and virulence.

\section{Sensitivities of Pro ${ }^{\mathrm{HR}}$ and $\mathrm{Pro}^{\mathrm{S}}$ isolates of $A$. alternata to stress agents}

The group III HK is involved in osmotic-regulatory signal transduction cascade of MAPK signaling pathway (Lin \& Chung 2010). To determine whether mutations in AaHK1 affect the sensitivity of A. alternata to osmotic and oxidative stresses, cell membrane permeability or cell wall integrity, the mycelial growth inhibition rates of the $\mathrm{Pro}^{\mathrm{HR}}$ and $\mathrm{Pro}^{\mathrm{S}}$ isolates on PDA supplemented with an osmotic stress agent $(1.2 \mathrm{M} \mathrm{KCl}$ or $1.2 \mathrm{M} \mathrm{NaCl})$, an oxidative stress agent $(10 \mathrm{mM}$ hydrogen peroxide, $\left.\mathrm{H}_{2} \mathrm{O}_{2}\right)$, a cell membrane stress agent $(0.05 \%$ Sodium dodecyl sulfate, SDS) or a cell wall damage agent $(0.05 \%$ Congo red, CR) were determined.

The data showed that all $\mathrm{Pro}^{\mathrm{HR}}$ isolates were strongly inhibited by $1.2 \mathrm{M} \mathrm{KCl}$ or $1.2 \mathrm{M} \mathrm{NaCl}$, with mycelial growth inhibition rates ranging from 84 to $95 \%$ or from 85 to $95 \%$, indicating that they were more sensitive to osmotic stresses than Pro ${ }^{\mathrm{S}}$ isolates $(51-78 \%$ and $64-78 \%$

Table $2 \mathrm{EC}_{50}$ values of Pro $^{\mathrm{S}}$ and Pro ${ }^{\mathrm{HR}}$ isolates of Alternaria alternata from broccoli and cabbage

\begin{tabular}{|c|c|c|c|c|c|}
\hline \multirow[t]{2}{*}{ Isolate } & \multirow[t]{2}{*}{ Sensitivity } & \multirow[t]{2}{*}{ Origin } & \multicolumn{3}{|l|}{$\mathrm{EC}_{50}(\mu \mathrm{g} / \mathrm{mL})$} \\
\hline & & & Procymidone & Iprodione & Fludioxonil \\
\hline $\mathrm{C} 10$ & Pro $^{5}$ & Cabbage & $0.73 \pm 0.13 d$ & $0.14 \pm 0.07 e$ & $0.068 \pm 0.005 \mathrm{~cd}$ \\
\hline $\mathrm{C} 28$ & Pro $^{\mathrm{s}}$ & Cabbage & $0.92 \pm 0.07 c$ & $0.53 \pm 0.03 c$ & $0.075 \pm 0.006 c$ \\
\hline B16 & Pro $^{s}$ & Broccoli & $0.95 \pm 0.11 c$ & $0.58 \pm 0.12 c$ & $0.073 \pm 0.006 c$ \\
\hline B21 & Pro $^{\mathrm{s}}$ & Broccoli & $0.98 \pm 0.08 c$ & $0.43 \pm 0.04 d$ & $0.085 \pm 0.004 c$ \\
\hline C5 & $\mathrm{Pro}^{\mathrm{HR}}$ & Cabbage & $>100 b$ & $>100 \mathrm{~b}$ & $>100 \mathrm{~b}$ \\
\hline C13 & Pro ${ }^{H R}$ & Cabbage & $>100 \mathrm{~b}$ & $>100 \mathrm{~b}$ & $>100 \mathrm{~b}$ \\
\hline$C 40$ & Pro ${ }^{H R}$ & Cabbage & $>100 b$ & $>100 b$ & $>100 \mathrm{~b}$ \\
\hline B30 & $\mathrm{PrO}^{\mathrm{HR}}$ & Broccoli & $>100 b$ & $>100 b$ & $>100 \mathrm{~b}$ \\
\hline B35 & Pro ${ }^{H R}$ & Broccoli & $>100 b$ & $>100 b$ & $>100 b$ \\
\hline B46 & Pro ${ }^{H R}$ & Broccoli & $>100 b$ & $>100 b$ & $>100 b$ \\
\hline B53 & Pro ${ }^{H R}$ & Broccoli & $>100 b$ & $>100 b$ & $>100 b$ \\
\hline B88 & Pro ${ }^{H R}$ & Broccoli & $>100 \mathrm{~b}$ & $>100 \mathrm{~b}$ & $>100 \mathrm{~b}$ \\
\hline B102 & Pro ${ }^{H R}$ & Broccoli & $>200 a$ & $>200 a$ & $>200 a$ \\
\hline B108 & Pro ${ }^{H R}$ & Broccoli & $>200 a$ & $>200 a$ & $>200 a$ \\
\hline
\end{tabular}

Means in a column followed by the same letter are not different according to Fisher's least significant difference $(P=0.05)$. Pro ${ }^{\mathrm{S}}$, procymidone-sensitive isolates; $\mathrm{PrO}^{\mathrm{HR}}$, high-level procymidone-resistant isolates; $\mathrm{EC}_{50}$, effective concentration for $50 \%$ inhibition of mycelial growth 


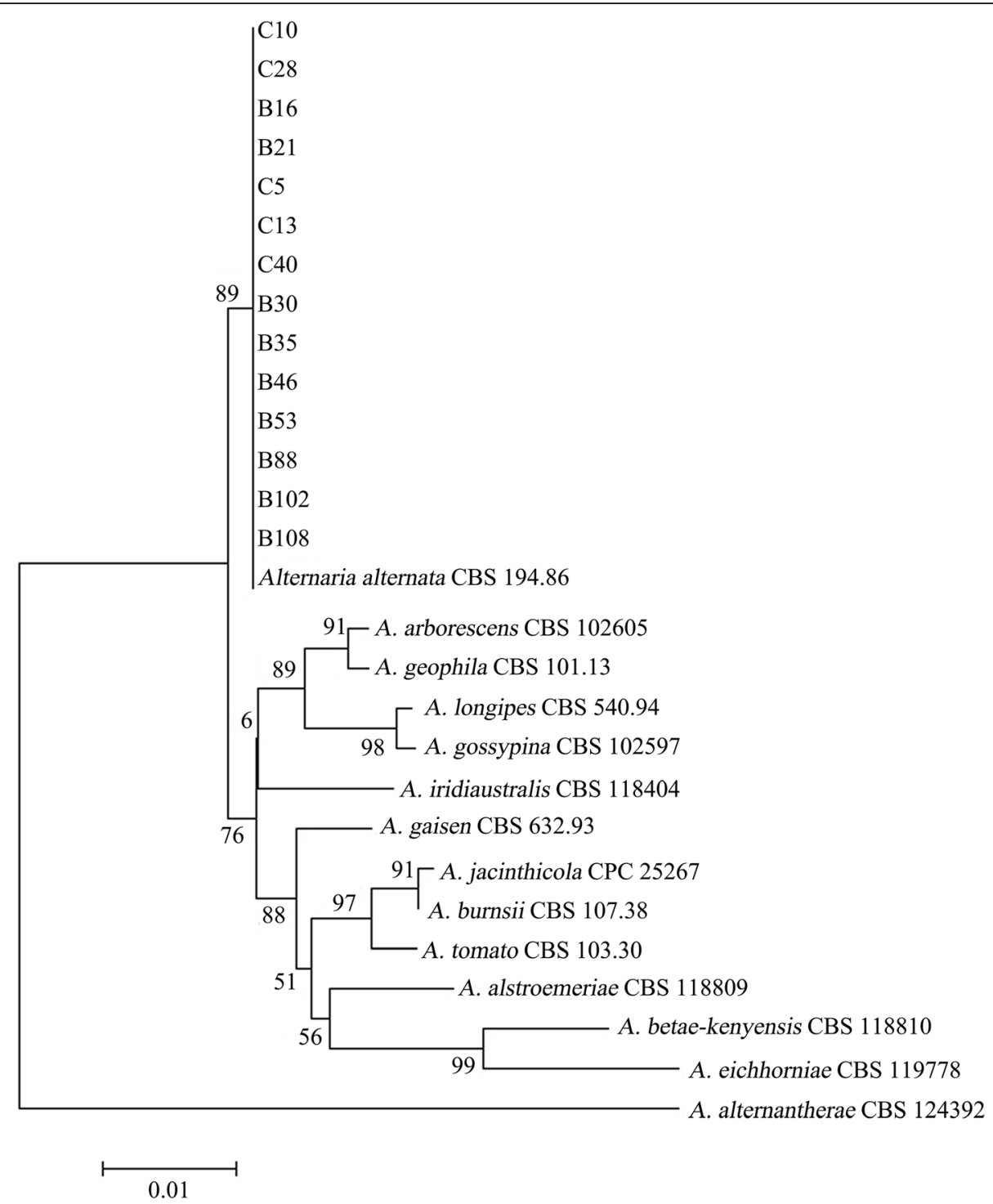

Fig. 1 Phylogram generated from maximum parsimony analysis based on sequences of ITS and KOG1058, showing the phylogenetic relationship of the tested isolates with A. alternata and other Alternaria species

mycelial growth inhibition by $1.2 \mathrm{M} \mathrm{KCl}$ and $1.2 \mathrm{M}$ $\mathrm{NaCl}$, respectively) $(P=0.05)$ (Fig. 3a, b). However, the mycelial growth rates of the Pro ${ }^{\mathrm{HR}}$ isolates were higher than those of the Pro ${ }^{S}$ isolates when treated with $0.05 \%$ SDS $(P=0.05)$ (Fig. 3c). Under $0.05 \%$ CR treatment condition, the radial growth rates of the Pro ${ }^{\mathrm{HR}}$ isolates displayed different degrees of inhibition relative to those of the Pro ${ }^{\mathrm{S}}$ isolates (Fig. 3d). Additionally, except for the Pro $^{\mathrm{HR}}$ isolate B102 (having no mutation in AaHK1), the mycelial growth rates of the Pro ${ }^{\mathrm{HR}}$ isolates were higher than those of the Pro ${ }^{\mathrm{S}}$ isolates when treated with $10 \mathrm{mM}$ $\mathrm{H}_{2} \mathrm{O}_{2}$ (Fig. 3e). Furthermore, the sensitivity to stress agents varied greatly among the $\mathrm{Pro}^{\mathrm{HR}}$ isolates from broccoli or cabbage.

\section{Mycelial intracellular glycerol accumulations (MIGAs) in Pro $^{\mathrm{HR}}$ and Pro ${ }^{\mathrm{S}}$ isolates of $A$. alternata}

DCFs are reported to affect glycerol biosynthesis and phosphorylation in HOG-MAPK pathway (Cui et al. 2002). Under procymidone-free condition, no significant difference was observed in MIGAs between the Pro ${ }^{\mathrm{S}}$ and Pro $^{\mathrm{HR}}$ isolates $(P>0.05)$. After treated with $10 \mu \mathrm{g} / \mathrm{mL}$ procymidone for $5 \mathrm{~h}$, MIGAs in Pro ${ }^{\mathrm{S}}$ isolates increased significantly and were 2.70-3.04 folds of those under procymidone-free condition, higher than that of $1.02-$ 1.27 folds by the ten Pro ${ }^{\mathrm{HR}}$ isolates under the same conditions $(P=0.05)$ (Fig. 4). Furthermore, no significant difference was observed in MIGAs among the Pro ${ }^{\mathrm{HR}}$ isolates from broccoli and cabbage $(P>0.05)$ (Fig. 4). 
Table 3 Mycelial growth rate, sporulation and virulence in Pro ${ }^{S}$ and Pro ${ }^{H R}$ isolates of Alternaria alternata from cabbage and broccoli

\begin{tabular}{|c|c|c|c|c|c|}
\hline Isolate & Sensitivity & Origin & Mycelial growth $(\mathrm{cm})$ & Sporulation $\left(\times 10^{5}\right.$ spores $\left./ \mathrm{mL}\right)$ & Virulence (lesion area, $\mathrm{cm}^{2}$ ) \\
\hline $\mathrm{C} 10$ & Pro $^{\mathrm{S}}$ & Cabbage & $7.49 \pm 1.15 a$ & $11.58 \pm 1.97 b c$ & $1.56 \pm 0.08 \mathrm{bc}$ \\
\hline $\mathrm{C} 28$ & Pro $^{\mathrm{S}}$ & Cabbage & $7.53 \pm 0.85 a$ & $10.15 \pm 1.03 c$ & $1.68 \pm 0.23 b$ \\
\hline B16 & Pro $^{\mathrm{S}}$ & Broccoli & $7.63 \pm 0.13 a$ & $9.95 \pm 0.95 \mathrm{~cd}$ & $1.53 \pm 0.26 b c$ \\
\hline B21 & Pro $^{\mathrm{S}}$ & Broccoli & $7.35 \pm 1.54 a$ & $12.63 \pm 1.32 b$ & $1.51 \pm 0.43 b c$ \\
\hline C5 & Pro ${ }^{H R}$ & Cabbage & $7.02 \pm 1.46 b$ & $0.28 \pm 0.09 \mathrm{gh}$ & $0.58 \pm 0.27 \mathrm{de}$ \\
\hline $\mathrm{C} 13$ & Pro ${ }^{H R}$ & Cabbage & $5.82 \pm 0.78 d$ & $2.59 \pm 0.15 \mathrm{e}$ & $1.05 \pm 0.64 c$ \\
\hline $\mathrm{C} 40$ & Pro ${ }^{H R}$ & Cabbage & $6.68 \pm 1.06 c$ & $0.61 \pm 0.12 \mathrm{~g}$ & $0.62 \pm 0.07 d$ \\
\hline B30 & Pro $H R$ & Broccoli & $5.37 \pm 0.53 \mathrm{ef}$ & $0.87 \pm 0.13 \mathrm{~g}$ & $0.55 \pm 0.14 \mathrm{de}$ \\
\hline B35 & Pro ${ }^{H R}$ & Broccoli & $5.53 \pm 0.84 e$ & $1.25 \pm 0.81 f$ & $2.38 \pm 0.84 a$ \\
\hline B46 & Pro ${ }^{H R}$ & Broccoli & $6.84 \pm 1.12 b c$ & $23.25 \pm 1.85 a$ & $0.46 \pm 0.12 \mathrm{e}$ \\
\hline B53 & Pro ${ }^{H R}$ & Broccoli & $6.51 \pm 0.25 c$ & $4.97 \pm 1.02 d$ & $2.05 \pm 0.23 a b$ \\
\hline B88 & Pro ${ }^{H R}$ & Broccoli & $6.91 \pm 0.66 b$ & $12.57 \pm 0.76 b$ & $0.63 \pm 0.04 d$ \\
\hline B102 & Pro ${ }^{H R}$ & Broccoli & $6.24 \pm 1.18 \mathrm{~cd}$ & $4.52 \pm 1.18 \mathrm{de}$ & $0.48 \pm 0.12 e$ \\
\hline B108 & Pro $H R$ & Broccoli & $5.65 \pm 0.57 \mathrm{de}$ & $0.97 \pm 0.08 \mathrm{~g}$ & $0.45 \pm 0.05 e$ \\
\hline
\end{tabular}

Radial mycelial growth of $A$. alternata isolate was measured after 7 days of incubation on potato dextrose agar (PDA) plates at $25^{\circ} \mathrm{C}$. Spores were harvested from the surface of 7-day-old PDA colony with sterile water (0.1\% Tween 20). Lesion areas were determined on broccoli leaves at 7 days post-inoculation (dpi). The mean value $\pm S D$ of each isolate was calculated from three independent experiments. Means in a column followed by the same letter are not different according to Fisher's least significant difference $(P=0.05)$. Pro ${ }^{\mathrm{S}}$, procymidone-sensitive isolates; $\mathrm{Pro}^{\mathrm{HR}}$, high-level procymidone-resistant isolates

\section{Sequence alignments of $A a H K 1$ from Pro ${ }^{\mathrm{S}}$ and Pro ${ }^{\mathrm{HR}}$ isolates of $A$. alternata}

To characterize mutations in AaHK1 proteins, the complete nucleotide sequences of $A a H K 1$ in all Pro ${ }^{\mathrm{HR}}$ and 20 arbitrarily selected Pro $^{S}$ isolates from broccoli and cabbage were sequenced and aligned. The results showed that the deduced AaHK1 protein is 1330 amino acids (aa) in length, possessing six HAMP repeat domains at $\mathrm{N}$ terminus, followed by a His Kinase A (phospho-acceptor) domain (HisKA), an HK-like ATPase domain (HATPase C), and a response regulator domain at C-terminus (Fig. 5). The twenty Pro ${ }^{\mathrm{S}}$ isolates possessed identical AaHK1 sequences with no genetic diversity, as illustrated by the four representative isolates $(\mathrm{C} 10, \mathrm{C} 28, \mathrm{~B} 16$ and $\mathrm{B} 21)$. No mutation was observed in $A a H K 1$ of all Pro ${ }^{\mathrm{LR}}$ isolates from broccoli and cabbage (data not show).

All mutations in the coding regions of $A a H K 1$ from Pro $^{\text {HR }}$ isolates are presented in Table 4. Except for the

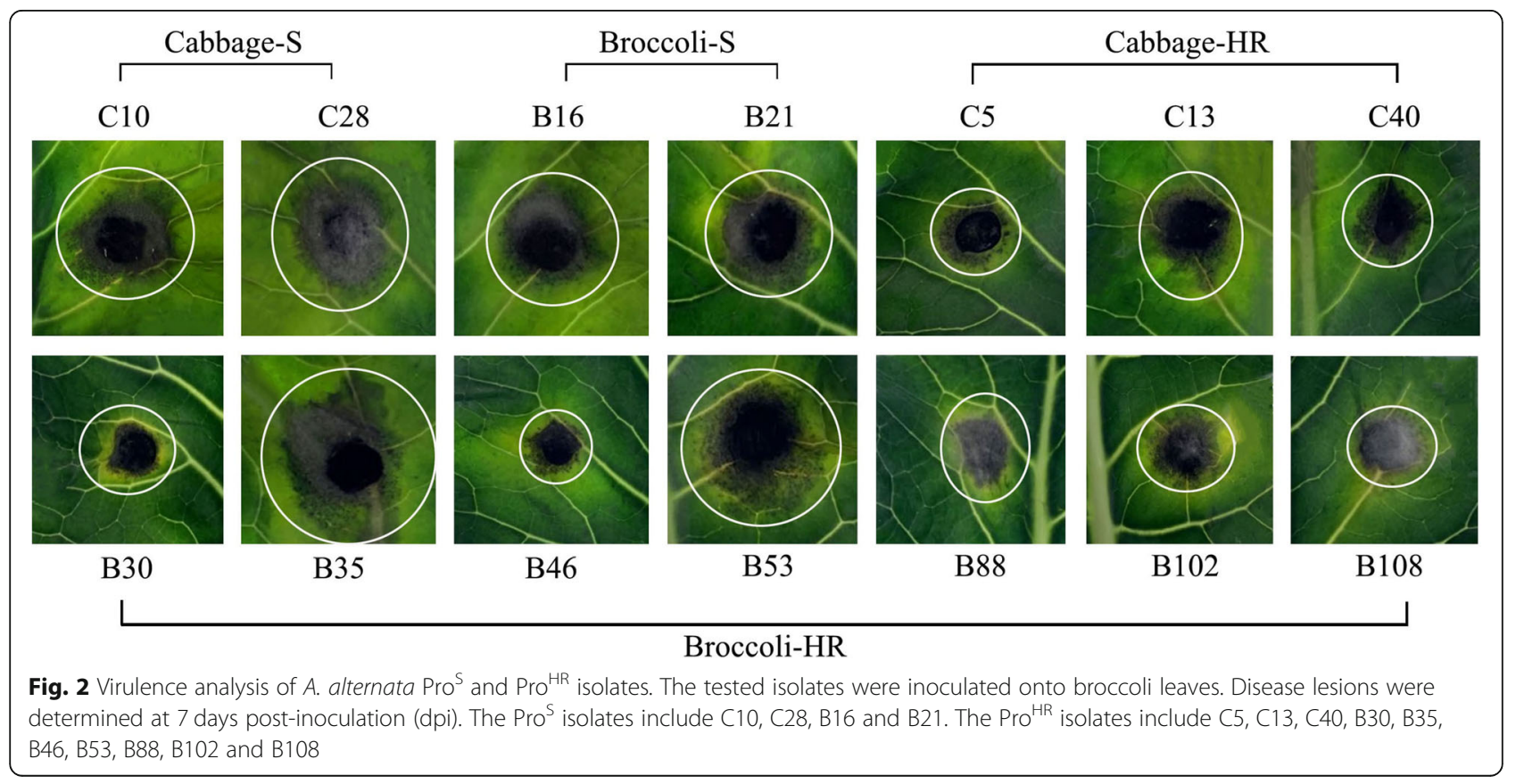




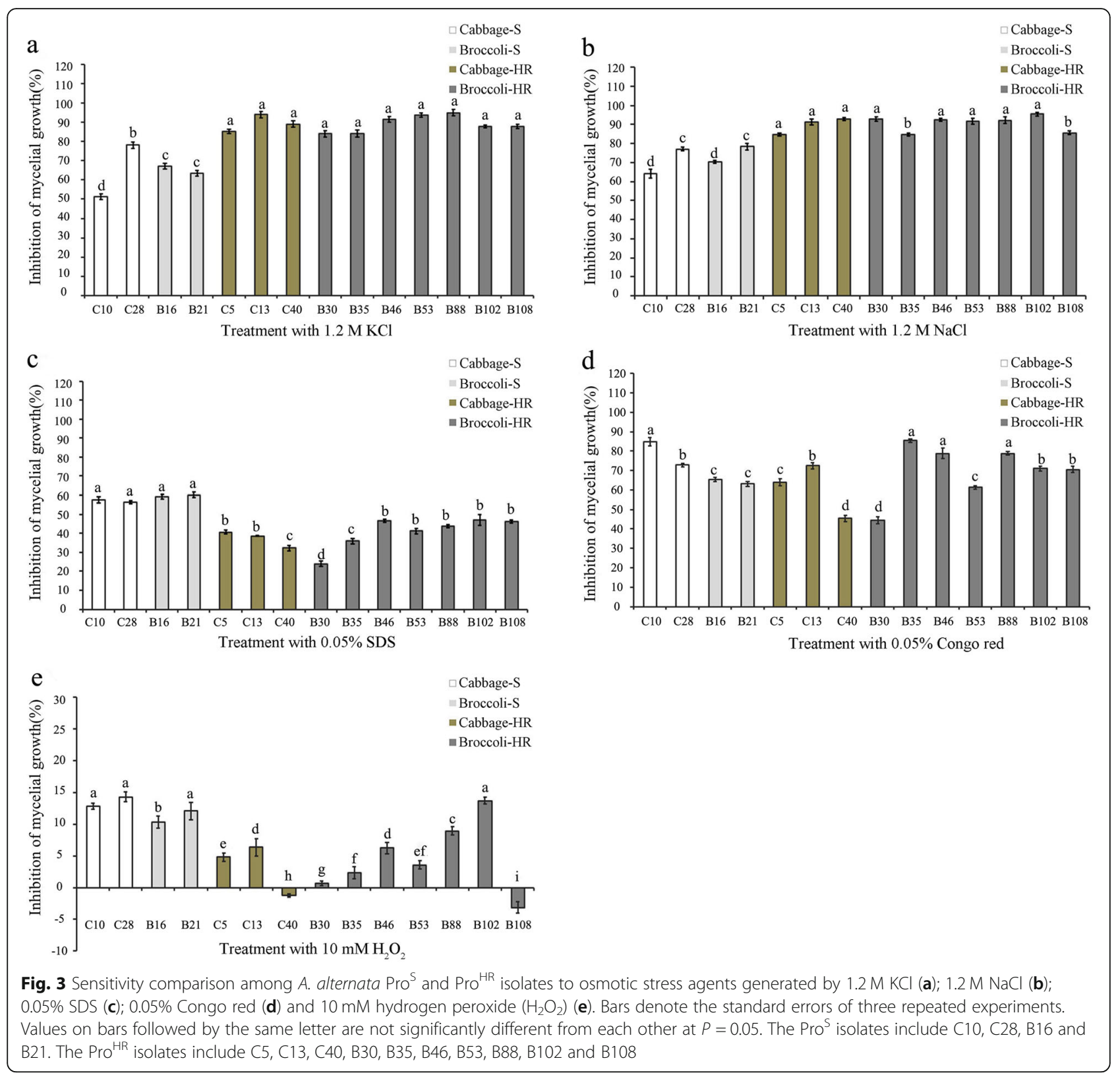

isolate B102, all broccoli-originated Pro ${ }^{\mathrm{HR}}$ isolates contained abundant amino acid mutations in AaHK1, which could be divided into two groups. Groups I possessed an amino acid substitution: E708K (a substitution of glutamic acid by lysine at codon ${ }^{708}$ within the HAMP6 domain) in isolates B88 and B108; V612L (a substitution of valine by leucine at $\operatorname{codon}^{612}$ within the HAMP6 domain) in isolate B30; Q924STOP (a precocious stop of translation at codon $^{924}$ within the HATPase_c domain) in isolate B35. Group II had a 2-bp deletion between domains of HATPase_c and Rec in isolate B53 (which caused a frame-shift, leading to premature termination at $\operatorname{codon}^{1104}$ of AaHK1), or a 381-bp deletion (from $\mathrm{nt}^{1707}$ to $\mathrm{nt}^{2089}$, causing a 127-AA deletion from HAMP4 to HAMP6) in isolate B46. In contrast, mutations in AaHK1 from three cabbage-originated Pro $^{\mathrm{HR}}$ isolates could be categorized into three groups: group I presented an amino acid substitution (P94A, proline was changed to alanine at $\operatorname{codon}^{94}$ localized between $\mathrm{N}$ terminus and HAMP1) in isolate C5; group II had an 8bp insertion at the Rec domain in isolate C40, resulting in a premature termination at codon ${ }^{1204}$; group III had a 552-bp deletion, causing a 184-AA deletion from HAMP1 to HAMP3 in isolate C13. In brief, diverse mutations were found in $\mathrm{Pro}^{\mathrm{HR}}$ isolates, and the resistant genotypes of $\mathrm{Pro}^{\mathrm{HR}}$ isolates from cabbage were distinct 


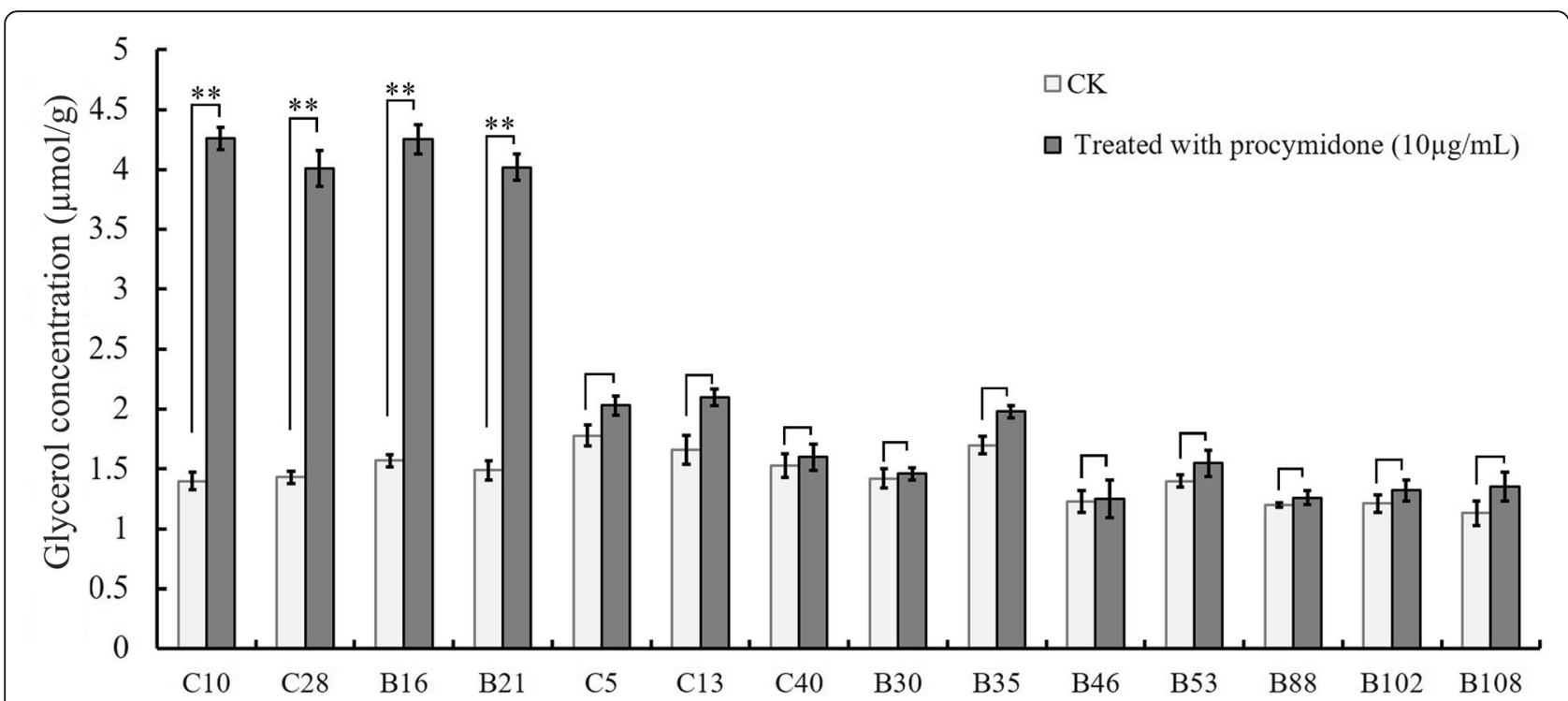

Fig. 4 Comparison of mycelial intracellular glycerol accumulations (MIGAs) among A. alternata Pro ${ }^{S}$ and Pro ${ }^{\mathrm{HR}}$ isolates. The mycelia of each isolate were treated with procymidone at 0 or $10 \mu \mathrm{g} / \mathrm{mL}$ after growth in PDB for $5 \mathrm{~h}$. Bars denote the standard errors of three repeated experiments. The asterisk indicates significant difference between procymidone-treated sample and control. The Pro ${ }^{\mathrm{S}}$ isolates include C10, C28, B16 and B21. The Pro $^{\mathrm{HR}}$ isolates include C5, C13, C40, B30, B35, B46, B53, B88, B102 and B108

from those from broccoli. Nucleotide sequence accession numbers corresponding to AaHK1 from the tested $\mathrm{Pro}^{\mathrm{HR}}$ and $\mathrm{Pro}^{\mathrm{S}}$ isolates are presented in Table 5.

\section{The relative expression level of $A a H K 1$ in Pro $^{\mathrm{S}}$ and Pro ${ }^{\mathrm{HR}}$ isolates of $A$. alternata}

The relative expression level of group III HK gene in $B$. cinerea is correlated with its resistance against histidine kinase inhibitors (Ren et al. 2016). Here, we investigated changes of AaHK1 expression in $\mathrm{Pro}^{\mathrm{S}}$ and $\mathrm{Pro}^{\mathrm{HR}}$ isolates against procymidone. In the absence of procymidone, the expression of $A a H K 1$ was relatively low in the Pro ${ }^{\mathrm{S}}$ and Pro ${ }^{\mathrm{HR}}$ isolates (Fig. 6). When treated with procymidone at $10 \mu \mathrm{g} / \mathrm{mL}$ for $12 \mathrm{~h}$, the relative expression level of AaHK1 in the Pro ${ }^{\mathrm{S}}$ isolates was 3.36-3.65 folds of that of untreated $\mathrm{Pro}^{\mathrm{S}}$ isolates, much higher than that of $0.89-1.22$ folds in the ten $\mathrm{Pro}^{\mathrm{HR}}$ isolates under the same condition (Fig. 6). Furthermore, no significant difference in the relative expression of $A a H K 1$ was observed among $\mathrm{Pro}^{\mathrm{HR}}$ isolates from two different hosts (broccoli and cabbage).

\section{Discussion}

Procymidone, a DCF fungicide for ALSB control, has been extensively used for decades in China, however, there is a growing concern about its decreased efficacy nowadays. Our data in this study indicate that DCFresistance has developed in natural populations of $A$. alternata from commercial fields of broccoli and cabbage in Yancheng, Jiangsu Province, China. Pro ${ }^{\text {LR }}$ populations developed faster than $\mathrm{Pro}^{\mathrm{HR}}$ populations in these fields during 2018-2019, and $\mathrm{Pro}^{\mathrm{HR}}$ populations from broccoli were larger than those from cabbage, which may be attributed to different selective pressures exerted by the use of a fungicide in different ways in the field. Long-term monitoring of population change should be performed to detect the dynamic of $\mathrm{Pro}^{\mathrm{HR}}$ population and formulate corresponding management strategy in time. To our knowledge, there has been no report so far on DCF-resistance in A. alternata from commercial fields of broccoli and cabbage.

DCF-resistance has been reported in several Alternaria species, including A. alternata (Dry et al. 2004), A. longipes (Luo et al. 2008), A. brassicicola (Avenot et al. 2005)

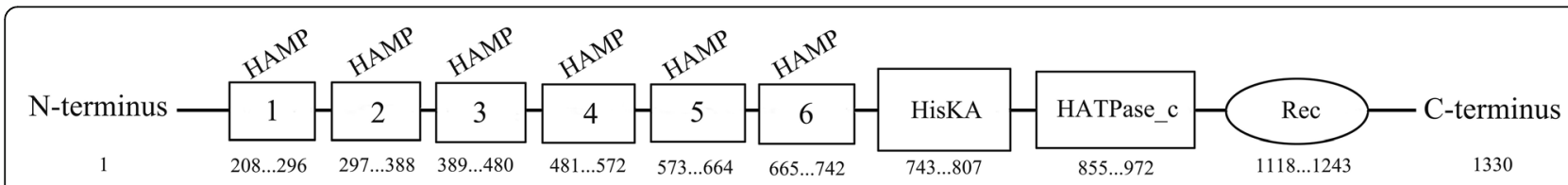

Fig. 5 Schematic representation of the AaHK1 protein coding region, including histidine kinase, adenylyl cyclase, methyl-accepting chemotaxis protein, and phosphatase domain repeats (HAMPs); His kinase A (phospho-acceptor) domain (HisKA); HK-like ATPase domain (HATPase_c); and response regulator domain (Rec) 
Table 4 Mutations in the coding regions of AaHK1 from Alternaria alternata Pro ${ }^{\mathrm{HR}}$ and Pro ${ }^{\mathrm{S}}$ isolates

\begin{tabular}{|c|c|c|c|c|}
\hline Isolate & Origin & $\begin{array}{l}\text { Nucleotide variation in coding } \\
\text { region }\end{array}$ & Mutation in amino acid sequence & Structural domain \\
\hline $\begin{array}{l}\mathrm{C} 10 \\
\mathrm{C} 28\end{array}$ & $\begin{array}{l}\text { Cabbage } \\
\text { /Pros }\end{array}$ & WT (N) & $\mathrm{N}$ & $\mathrm{N}$ \\
\hline $\begin{array}{l}\text { B16, } \\
\text { B21 }\end{array}$ & $\begin{array}{l}\text { Broccoli } \\
\text { /Pro }^{5}\end{array}$ & WT (N) & $\mathrm{N}$ & $\mathrm{N}$ \\
\hline C5 & $\begin{array}{l}\text { Cabbage } \\
\text { /Pro }\end{array}$ & CCC to GCC at $\mathrm{nt}^{280}$ & P94A & $\begin{array}{l}\text { Between N-terminus and } \\
\text { HAMP1 }\end{array}$ \\
\hline $\mathrm{C} 13$ & $\begin{array}{l}\text { Cabbage } \\
\text { /Pro }\end{array}$ & $\begin{array}{l}\text { 552-bp deletion between } \mathrm{nt}^{791}- \\
\mathrm{nt}^{1344}\end{array}$ & A deletion of 184-AA residues & $\begin{array}{l}\text { Between HAMP } 1 \text { and } \\
\text { HAMP } 3\end{array}$ \\
\hline $\mathrm{C} 40$ & $\begin{array}{l}\text { Cabbage } \\
\text { /Pro }\end{array}$ & $\begin{array}{l}\text { 8-bp insertion between } \mathrm{nt}^{3294}- \\
\mathrm{nt}^{3295}\end{array}$ & $\begin{array}{l}\text { Frameshift mutation leading to premature termination at } \\
\text { the codon } 204\end{array}$ & $\operatorname{Rec}$ \\
\hline B30 & $\begin{array}{l}\text { Broccoli } \\
/ \text { Pro }\end{array}$ & GTG to CTG at nt ${ }^{1834}$ & V612L & HAMP5 \\
\hline $\begin{array}{l}\text { B88, } \\
\text { B108 }\end{array}$ & $\begin{array}{l}\text { Broccoli } \\
\text { /PrO }^{\mathrm{HR}}\end{array}$ & GAG to $A A G$ at $\mathrm{nt}^{2122}$ & E708K & HAMP6 \\
\hline B35 & $\begin{array}{l}\text { Broccoli } \\
\text { /Pro }\end{array}$ & CAG to TAG at nt ${ }^{2770}$ & Q924STOP & HATPase_c \\
\hline B46 & $\begin{array}{l}\text { Broccoli } \\
\text { /Pro }^{H R}\end{array}$ & $\begin{array}{l}\text { 381-bp deletion between } \mathrm{nt}^{1707}- \\
\mathrm{nt}^{2089}\end{array}$ & A deletion of 127-AA residues & $\begin{array}{l}\text { Between HAMP4 and } \\
\text { HAMP6 }\end{array}$ \\
\hline B53 & $\begin{array}{l}\text { Broccoli } \\
\text { /Pro }\end{array}$ & $\begin{array}{l}\text { 2-bp deletion between } \mathrm{nt}^{3249}- \\
\mathrm{nt}^{3252}\end{array}$ & $\begin{array}{l}\text { Frameshift mutation leading to premature termination at } \\
\text { the codon } 1104\end{array}$ & $\begin{array}{l}\text { Between HATPase_c and } \\
\text { Rec }\end{array}$ \\
\hline B102 & $\begin{array}{l}\text { Broccoli } \\
\text { /PrO }^{\mathrm{HR}}\end{array}$ & $\mathrm{N}$ & $\mathrm{N}$ & $\mathrm{N}$ \\
\hline
\end{tabular}

$\mathrm{Pro}^{\mathrm{S}}$, procymidone-sensitive isolates; Pro $^{\mathrm{HR}}$, high-level procymidone-resistant isolates; $\mathrm{WT}$, wild type; $\mathrm{nt}$, nucleotide; $\mathrm{N}$, no mutation

and A. arborescens (Ma \& Michailides 2004). However, the resistance mechanism of these fungal pathogens to DCFs and phenylpyrroles has not yet been determined. To elucidate the possible molecular mechanism of DCF-

Table 5 Nucleotide sequence accession numbers corresponding to AaHK1 from Pro ${ }^{\mathrm{HR}}$ and Pro ${ }^{\mathrm{S}}$ isolates of Alternaria alternata in this study

\begin{tabular}{llll}
\hline Isolate & Origin & Accession number & Reference \\
\hline C10 & Cabbage/Pro $^{\text {S }}$ & MZ268605 & This article \\
C28 & Cabbage/Pro $^{\text {S }}$ & MZ268606 & This article \\
B16 & Broccoli/Pro $^{\text {S }}$ & MZ268607 & This article \\
B21 & Broccoli/Pro $^{\text {S }}$ & MZ268608 & This article \\
C5 & Cabbage/Pro $^{\text {HR }}$ & MZ268609 & This article \\
C13 & Cabbage/Pro $^{H R}$ & MZ268610 & This article \\
C40 & Cabbage/Pro $^{\text {HR }}$ & MZ268611 & This article \\
B30 & Broccoli/Pro $^{\text {HR }}$ & MZ268612 & This article \\
B88 & Broccoli/Pro $^{\text {HR }}$ & MZ268613 & This article \\
B108 & Broccoli/Pro $^{\text {HR }}$ & MZ268614 & This article \\
B35 & Broccoli/Pro $^{\text {HR }}$ & MZ268615 & This article \\
B46 & Broccoli/Pro $^{\text {HR }}$ & MZ268616 & This article \\
B53 & Broccoli/Pro $^{\text {HR }}$ & MZ268617 & This article \\
B102 & Broccoli/Pro $^{\text {HR }}$ & MZ268618 & This article \\
\hline
\end{tabular}

Pro $^{\mathrm{S}}$, procymidone-sensitive isolates; Pro $^{\mathrm{HR}}$, high-level procymidone-resistant isolates resistance, the nucleotide sequences of $A a H K 1$ of $A$. alternata $\operatorname{Pro}^{\mathrm{HR}}$ isolates from broccoli and cabbage were sequenced and aligned in this study. The results demonstrate that a high level of nucleotide sequence homology exists between $A a H K 1$ and $o s-1$ from $N$. crassa (Ochiai et al. 2010), B. cinerea (Ren et al. 2016), A. brassicicola (Avenot et al. 2005) and A. longipes (Luo et al. 2008).

Abundant mutation types were detected in AaHK1 of the Pro ${ }^{\mathrm{HR}}$ isolates from cabbage and broccoli, including deletions at HAMPs or between HATPase_c and Rec domains, an insertion at the Rec domain, amino acid substitutions at HAMPs or HATPase_c domain. The observed premature termination mutations in AaHK1 were generated by a 2-bp deletion, an 8-bp insertion or $\mathrm{C}$ to $\mathrm{T}$ transition. Intriguingly, no mutation was detected in AaHK1 of $\mathrm{B} 102$ (a Pro ${ }^{\mathrm{HR}}$ isolate from broccoli), with the same situation occurring in DCF-resistant isolates of $A$. alternata (from pistachio), A. arborescens (Ma \& Michailides 2004) and A. brassicicola (Avenot et al. 2005). Additionally, in DCF-resistant $A$. alternata isolates from passionfruit, frameshift mutations caused by a 4-bp and an 11-bp insertion at HAMP5 and HAMP1 of AaHK1, respectively, confer resistance to DCFs (Dry et al. 2004). The diverse mutations are also found in homologous HK1s of other Alternaria species. The iprodioneresistant $A$. brassicicola isolates possess an amino acid substitution (E to K) at the HisKA domain, a frameshift caused by a 2-bp deletion at HAMP4, or nonsense 


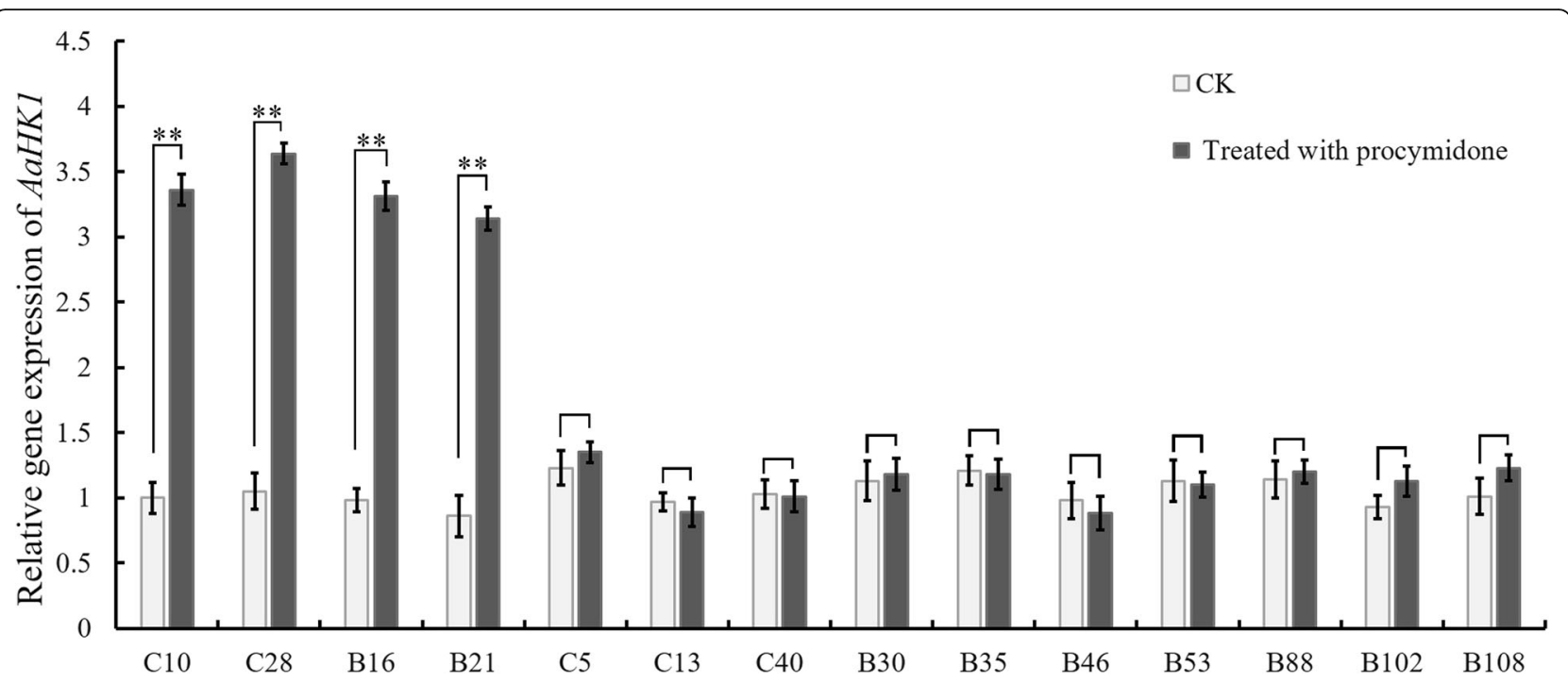

Fig. 6 The expression of $A a H K 1$ gene in A. alternata Pro ${ }^{S}$ and Pro ${ }^{H R}$ isolates. The mycelia of each isolate were treated with procymidone at 0 or $10 \mathrm{\mu g} / \mathrm{mL}$ after growth in PDB for $12 \mathrm{~h}$. Bars denote the standard errors of three repeated experiments. The asterisk indicates significant difference

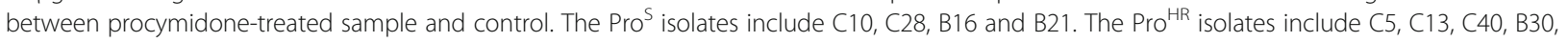
B35, B46, B53, B88, B102 and B108

mutations at HAMPs or HATPase_c domains in AbNIK1 (Avenot et al. 2005), while the dimethachlonresistant $A$. longipes isolates possess amino acid substitutions at HAMPs, nonsense mutation generated by amino acid substitution at HAMP5, or a 321-bp deletion between HAMP5 and HAMP6 of AlHK1 (Luo et al. 2008). All the mutations detected at different domains of HKs in DCF-resistant isolates might affect their corresponding biochemical characteristics, including the resistance against DCFs. In this study, although not all $A$. alternata Pro ${ }^{\mathrm{HR}}$ isolates possessed mutation in $A a H K 1$, this might be the dominant mechanism involved in their DCFresistance.

In yeast and $B$. cinerea, cellular responses to osmotic stress are controlled by the HOG-MAPK signaling pathway through which a range of osmotic responses including glycerol synthesis are regulated (Brewster et al. 1993; Cui et al. 2002). In this study, when treated with $10 \mu \mathrm{g} /$ $\mathrm{mL}$ procymidone, MIGAs and the expression level of AaHK1 were significantly increased in the Pro ${ }^{\mathrm{S}}$ isolates compared with those under procymidone-free conditions, while this increase in the ten Pro ${ }^{\mathrm{HR}}$ isolates was at a relatively low level, the same as that observed in fludioxonil-resistant B. cinerea isolates (Ren et al. 2016). The results indicate that AaHK1 plays a role in the HOG-MAPK pathway, and a negative correlation exists between the resistance level of $A$. alternata to procymidone and the increase of MIGAs under procymidonestressed condition. It was reported that the high level iprodione- or fludioxonil-resistant isolates of A. alternata from passionfruit exhibited moderate sensitivity to osmotic stress, identical to that of A. brassicicola (Dry et al. 2004; Avenot et al. 2005). Nevertheless, in this study, all the Pro ${ }^{\mathrm{HR}}$ isolates from broccoli and cabbage were highly sensitive to osmotic stresses. The difference in sensitivity to osmotic stress agents in Alternaria spp. suggest that mutations in $H K 1 s$ might affect signal transduction of the HOG-MAPK signaling pathway, consequently resulting in distinct responses to stress agents.

For other regulatory functions of HK1s in the development of DCF-resistance, Steel (Steel 1996) reported that the resistance to DCFs is positively correlated with the activity of an anti-oxidant enzyme, catalase. Compared with Pro ${ }^{\mathrm{S}}$ isolates, the sensitivity of Pro ${ }^{\mathrm{HR}}$ isolates (with mutations in AaHK1) to oxidative stress $\left(\mathrm{H}_{2} \mathrm{O}_{2}\right)$ was reduced significantly, whereas, no significant difference in sensitivity to $\mathrm{H}_{2} \mathrm{O}_{2}$ was observed in B102, a Pro ${ }^{\mathrm{HR}}$ isolate having no mutations in $A a H K 1$. This suggests that mutations leading to inactivation of HK1 may result in constitutive induction of catalase, as observed in DCFresistant $B$. cinerea and $A$. alternata isolates from passionfruit (Steel \& Nair 1995; Steel 1996). In contrast, the sensitivity to oxidative stress in HK mutants of $A$. longipes from tobacco was not affected (Luo et al. 2012). These results indicate that $\mathrm{HKs}$ from $A$. alternata and $A$. longipes have a different regulatory function in signal transduction during oxidative stress. In addition, all Pro ${ }^{\mathrm{HR}}$ isolates were more resistant to cell membrane agent $(0.05 \%$ SDS $)$ than those of Pro ${ }^{\mathrm{S}}$ isolates, indicating that the group III HK of A. alternata is probably associated with membrane permeability. The enhanced tolerance to $\mathrm{H}_{2} \mathrm{O}_{2}$ and SDS in Pro ${ }^{\mathrm{HR}}$ isolates is suggested to protect their cells from the deleterious effects of DCFs. 
Fitness is an extremely essential parameter for evaluation of the potential risk of fungicide-resistant populations. Many DCF-resistant isolates display a fitness penalty relative to DCF-sensitive isolates, as those found in S. sclerotiorum (Kuang et al. 2011), B. cinerea (Ren et al. 2016) and Penicillium expansum (Li \& Xiao 2008). Although most Pro ${ }^{\mathrm{HR}}$ isolates of A. alternata in current study was also reduced in mycelial growth rate, sporulation capacity and virulence, the Pro ${ }^{\mathrm{HR}}$ isolates B46, B35 and B53 were increased significantly in sporulation capacity or pathogenicity compared with $\mathrm{Pro}^{\mathrm{S}}$ isolates. This suggests that $\mathrm{Pro}^{\mathrm{HR}}$ populations of A. alternata from commercial fields of broccoli and cabbage as a whole possessed no superiority over $\operatorname{Pro}^{\mathrm{S}}$ populations (wild type), and was in a stage of slow development in these fields during 2018-2019. However, the $\mathrm{Pro}^{\mathrm{HR}}$ isolates with high fitness may have the potential to develop into a large group if no reasonable control methods are adopted. Therefore, the growers should be encouraged to use mixed fungicides with different modes of action (e.g., QoIs, DMIs or SDHIs) to delay the development of DCF-resistant $A$. alternata populations in these fields.

\section{Conclusions}

The resistance to procymidone has developed in natural populations of A. alternata infecting broccoli and cabbage crops in Jiangsu Province of China. Most Pro ${ }^{H R}$ isolates displayed a fitness penalty in mycelial growth rate, sporulation and virulence compared with $\operatorname{Pro}^{\mathrm{S}}$ isolates. The $\operatorname{Pro}^{\mathrm{HR}}$ isolates were highly sensitive to osmotic stress. In addition, a positive cross-resistance was observed between procymidone and fludioxonil or iprodione. Mutations in $A a H K 1$ were involved in the resistance of $A$. alternata isolates to DCFs. No significant differences in biochemical characteristics was observed between $\mathrm{Pro}^{\mathrm{HR}}$ isolates from broccoli and cabbage.

\section{Methods \\ Sample collection, causal agent isolation and identification}

All the 198 isolates of $A$. alternata were isolated from symptomatic leaves during 2018-2019. Diseased leaves were collected from different commercial fields of broccoli and cabbage at Yancheng City, Jiangsu Province, China, where procymidone (a member of DCFs), alone or mixed with other fungicides with different mode of action, had been extensively used to control ALSB twice or three times in a growing stage since 1980s. Any two neighboring samples were separated from each other at least $50 \mathrm{~m}$, with each sample placed in an individual envelope. To obtain $A$. alternata isolates, small tissue pieces cut from lesion edges were sterilized in $1 \% \mathrm{NaClO}$ for $3 \mathrm{~min}$, washed three times with sterile distilled water, and transferred onto Petri dishes containing PDA medium supplemented with $100 \mu \mathrm{g} / \mathrm{mL}$ streptomycin sulfate (Solarbio Science \& Technology Co., Ltd.) (Ren et al. 2016). After incubation at $25^{\circ} \mathrm{C}$ for 6 days, a mycelial plug was cut from the margin of an actively growing colony, and transferred to the center of a fresh PDA plate. Conidia were harvested using sterile distilled water after 6 days of incubation at $25^{\circ} \mathrm{C}$, and the single-spore isolate was obtained by picking a single conidium under a microscope (Zhang et al. 2017). In total, 198 singlespore isolates were obtained. The representative isolates were further identified by polymerase chain reactions (PCR) with two primer pairs ITS1/ITS4 and KOG1058F/ KOG1058R (Table 6) (Woudenberg et al. 2015). The ITS and KOG1058 sequences of each isolate were blasted and congeneric sequences were obtained from the National Center for Biotechnology Information (NCBI) GenBank database. Phylogram analysis was processed by MEGA7 software based on ITS and KOG1058 sequences to further identify the isolates.

\section{Fungicides}

All fungicides used are technical grade. Fludioxonil and iprodione (98\% active ingredient; generously provided by Yangzhou Younuo Chemicals Co., Ltd., Yangzhou, China) were dissolved in methanol to obtain a stock solution of $2 \times 10^{4} \mathrm{mg} / \mathrm{L}$. Procymidone $(99.2 \%$ active ingredient; provided by Jiangsu Xinyi Chemical Co., Ltd., Xuzhou, China) was dissolved in acetone to obtain a stock solution of $2 \times 10^{4} \mathrm{mg} / \mathrm{L}$. All stock solutions were kept at $4{ }^{\circ} \mathrm{C}$ before use.

\section{Determination of resistance frequencies of $A$. alternata isolates to procymidone}

Sensitivities of 198 single-conidium isolates of $A$. alternata to procymidone were determined by discriminatory doses of mycelial growth inhibition method. In brief, procymidone at $0,10,50$ and $100 \mu \mathrm{g} / \mathrm{mL}$ were used to determine sensitivities of all isolates for low-resistance (LR), moderate-resistance (MR) and high-resistance (HR). The isolate was considered procymidone-sensitive $\left(\mathrm{Pro}^{\mathrm{S}}\right.$ ) when the MIC (minimum inhibitory concentration) value was less than $10 \mu \mathrm{g} / \mathrm{mL}$. Similarly, $10<\mathrm{MIC}<$ $50 \mu \mathrm{g} / \mathrm{mL}$ for low-level procymidone-resistant (Pro ${ }^{\mathrm{LR}}$ ) isolates, $\quad 50<\mathrm{MIC}<100 \mu \mathrm{g} / \mathrm{mL}$ for moderate-level procymidone-resistant $\left(\mathrm{Pro}^{\mathrm{MR}}\right)$ isolates, and $\mathrm{MIC}>$ $100 \mu \mathrm{g} / \mathrm{mL}$ for high-level procymidone-resistant (Pro ${ }^{\mathrm{HR}}$ ) isolates. Mycelial plugs (5 $\mathrm{mm}$ in diameter) were cut from the margin of a 6-day-old colony, and transferred to the center of Petri dishes containing PDA medium (one plug per dish) amended with procymidone at the above-mentioned concentrations. At 6 days of incubation, the sensitivity of each isolate to procymidone was determined based on the mycelial colony growth 
Table 6 Primers used in this study

\begin{tabular}{|c|c|c|c|}
\hline Primer set & Forward primer $\left(5^{\prime}-3^{\prime}\right)$ & Reverse primer $\left(5^{\prime}-3^{\prime}\right)$ & Description $^{\mathrm{a}}$ \\
\hline 1 & TGTGGCTTGCGGTTATTC & CGACGGCAGTGACGATG & $\begin{array}{l}\text { Amplification of AaHK1 from } \\
-128 \text { to }+820\end{array}$ \\
\hline 2 & AGCCAGGAAGTGAATAAGCA & TTCGTCGAGTCTCATAAC & $\begin{array}{l}\text { Amplification of AaHK1 from } \\
+726 \text { to }+2097\end{array}$ \\
\hline 3 & CAACAATGTCAACACTATGG' & CTTCTCCGAGCTCAGTAAAC & $\begin{array}{l}\text { Amplification of AaHK1 from } \\
+1914 \text { to }+2705\end{array}$ \\
\hline 4 & GAATGACCCAACTTACGCT & CATAAGTACGCAATCGTAAC & $\begin{array}{l}\text { Amplification of AaHK1 from } \\
+2598 \text { to }+3672\end{array}$ \\
\hline 5 & ATGACGACGCCCTGTCTACC & ATCCAATACACACAAAAATG & $\begin{array}{l}\text { Amplification of AaHK1 from } \\
+3551 \text { to }+4505\end{array}$ \\
\hline 6 & TCCGTAGGTGAACCTGCGG & TCCTCCGCTTATTGATATGC & $\begin{array}{l}\text { Amplification of ITS } \\
\text { to identify A. alternata }\end{array}$ \\
\hline 7 & GAGTCACGTTAYCGCASC & TGGCTKACGGARACG & $\begin{array}{l}\text { Amplification of KOG } 1058 \\
\text { to identify A. alternata }\end{array}$ \\
\hline 8 & ACGCTTCTCATCTCCAAGATCCGT & AGAGAGCCTCGTTGTCAATGCAGA & $\begin{array}{l}\text { Amplification of } \beta \text {-tubulin } \\
\text { for } \mathrm{qPCR}\end{array}$ \\
\hline 9 & CTTACAAGGTGCCCGACTAC & GATCTGGGTCGCATTCTTGT & QPCR primers for analysis of AaHK1 expression \\
\hline
\end{tabular}

${ }^{\mathrm{a}}$ For primer set $1-5$, the first nucleotide of the start codon in the AaHK1 gene was considered as position +1

inhibited by procymidone. The resistance frequency was determined using the following formula: resistance frequency $(\%)=($ the number of resistant isolates/the number of the total isolates tested) $\times 100 \%$. The experiment was performed three times with three replications for each isolate.

\section{Determination of sensitivities of $A$. alternata isolates to procymidone}

To determine the sensitivity of A. alternata isolates to procymidone, the fungicide was prepared in a serial concentrations of $0,25,50,100,200,400$ and $800 \mu \mathrm{g} / \mathrm{mL}$ for Pro $^{\mathrm{HR}}$ isolates, and another serial concentrations of 0 , $0.03,0.1,0.3,1,3$ and $9 \mu \mathrm{g} / \mathrm{mL}$ for Pro $^{\mathrm{S}}$ isolates. The 6day-old mycelial plugs $(5 \mathrm{~mm}$ in diameter) were separately transferred to the center of PDA plates with abovementioned concentrations of procymidone. Percentage of inhibition was evaluated and $\mathrm{EC}_{50}$ (effective concentration for 50\% mycelial inhibitive growth) was calculated for each tested isolate using Data Processing System (DPS 7.05). The experiment was performed three times with three replications for each isolate.

\section{Cross-resistance test among different fungicides}

The sensitivity of A. alternata isolates to fludioxonil and iprodione were determined by measuring mycelial growth rate. One serial concentrations $(0,25,50,100$, 200,400 and $800 \mu \mathrm{g} / \mathrm{mL}$ ) were set up to test the sensitivity of resistant isolates to fludioxonil or iprodione, and another serial concentrations $(0,0.025,0.05,0.1,0.2,0.4$, 0.8 and $1.6 \mu \mathrm{g} / \mathrm{mL}$ ) for sensitive isolates. $\mathrm{EC}_{50}$ values were determined with the same method as abovementioned. Spearman's rank correlation coefficient for the $\log _{10}$-transformed $\mathrm{EC}_{50}$ values was used to analyze cross-resistance pattern between procymidone and fludioxonil or iprodione. The experiment was performed three times with four replicates per concentration.

\section{Determination of radial growth rates and sporulation capacities of $A$. alternata isolates}

Six-day-old mycelial plugs $(5 \mathrm{~mm}$ in diameter) of $A$. alternata isolates were transferred to the center of Petri dishes containing PDA medium (one plug per dish), then placed in an incubator at $25^{\circ} \mathrm{C}$ in darkness. At 6 days of incubation, the average colony diameter for each isolate was measured in two perpendicular directions. The experiment was performed three times with three replications for each isolate.

For sporulation test, conidia were harvested from the surface of six-day-old PDA colonies washed with $10 \mathrm{~mL}$ sterile water (containing 0.1\% Tween 20), filtered through four layers of sterile lens papers, and centrifuged at 5000 $\mathrm{rpm}$ for $1 \mathrm{~min}$. The pellets were re-suspended in $1 \mathrm{~mL}$ sterile distilled water. The concentrations of conidial suspensions were measured with a hemacytometer under microscope. Six replicates were performed for each isolate, and the experiment was repeated three times.

\section{Virulence assay}

Broccoli (var. Hanxiu) leaves were used to determine the pathogenicity of $A$. alternata isolates. Leaves were surface-disinfected with $75 \%$ alcohol for $10 \mathrm{~s}$, and inoculated with six-day-old hyphal plugs ( $5 \mathrm{~mm}$ in diameter) of each isolate. Before inoculation, a sterilized needle was used to produce wound. All the inoculated leaves were transferred onto three layers of moistened filter 
paper, and incubated at $25^{\circ} \mathrm{C}$ with $85 \%$ relative humidity (RH) and a 12-h light/12-h dark cycle. The lesion areas were calculated at $7 \mathrm{dpi}$ (days post-inoculation). The experiment was performed three times.

\section{Determination of responses of $A$. alternata isolates to various environmental stresses}

To evaluate responses of $A$. alternata isolates to different stress agents, all isolates were incubated at $25^{\circ} \mathrm{C}$ for 6 days. Then, mycelial plugs $(5 \mathrm{~mm}$ in diameter) were cut from the edge of actively growing colonies, and transferred onto PDA plates amended with $0.05 \%$ sodium dodecyl sulfate (SDS) (w/v), $0.05 \%$ Congo red (CR) $(\mathrm{w} / \mathrm{v}), 1.2 \mathrm{M} \mathrm{KCl}, 1.2 \mathrm{M} \mathrm{NaCl}$ or $10 \mathrm{mM}$ hydrogen peroxide $\left(\mathrm{H}_{2} \mathrm{O}_{2}\right)(\mathrm{v} / \mathrm{v})$. The isolates incubated in PDA plates without stress agents were served as controls. All treatments were incubated for 6 days at $25^{\circ} \mathrm{C}$, with three replicate plates for each agent. The inhibition percentages of mycelial growth by these stress agents were determined for each tested isolate. This experiment was performed three times.

\section{Determination of intracellular glycerol accumulations in \\ A. alternata isolates}

A commercial assay kit (Applygen Technologies Inc., Beijing) was used to determine intracellular glycerol accumulations in mycelia of $A$. alternata isolates in accordance with the manufacturer's instruction. In brief, all isolates were incubated in potato dextrose broth (PDB) in a shaker $(175 \mathrm{rpm})$ at $25^{\circ} \mathrm{C}$ for 2 days. At $5 \mathrm{~h}$ after treatment with $10 \mu \mathrm{g} / \mathrm{mL}$ procymidone, mycelia of each isolate were collected with sterile distilled water, lyophilized and grounded in mortars amended with liquid nitrogen (Ren et al. 2016). Mycelial powder (0.1 g) was then transferred into a $2 \mathrm{~mL}$ centrifuge tube, and mixed in $1 \mathrm{~mL}$ glycerol extraction buffer (Applygen Technologies Inc., Beijing, China). The mixture was vortexed for $5 \mathrm{~min}$ and centrifuged at $5000 \mathrm{rpm}$ for $20 \mathrm{~min}$, and the supernatants were used to analyze mycelial intracellular glycerol concentrations (Duan et al. 2013). This experiment was repeated three times with four replicates for each isolate.

\section{DNA extraction and sequence analysis of AaHK1}

Genomic DNAs were extracted from mycelia of $A$. alternata isolates with a commonly used cetyltrimethylammonium bromide (CTAB) method. Based on the sequence of AaHK1 (GenBank accession No. GQ414508.1) deposited in NCBI GenBank database, five primer pairs (Table 6) were designed to amplify the complete nucleotide sequence of AaHK1. Polymerase chain reactions (PCR) were conducted in a $25 \mu \mathrm{L}$ volume, containing $0.25 \mu \mathrm{L}$ of high-fidelity LA polymerase $(5 \mathrm{U} / \mathrm{mL})$ (TaKaRa, Japan), $1 \mu \mathrm{L}$ of each primer $(10 \mathrm{mM})$,
$2.5 \mu \mathrm{L}$ of $10 \times$ LA polymerase buffer $\left(\mathrm{Mg}^{2+}\right.$ free), $50 \mathrm{ng}$ of genomic DNA, $2.5 \mu \mathrm{L}$ of $\mathrm{MgCl}_{2}(25 \mathrm{mM}), 4 \mu \mathrm{L}$ of dNTP mixture (2.5 mM of each dNTP) and $12.75 \mu \mathrm{L}$ of $\mathrm{ddH}_{2} \mathrm{O}$. The PCR program consisted of an initial denaturation at $94^{\circ} \mathrm{C}$ for $5 \mathrm{~min}$; followed by 35 cycles of denaturation at $94{ }^{\circ} \mathrm{C}$ for $30 \mathrm{~s}$, annealing at $56^{\circ} \mathrm{C}$ for $30 \mathrm{~s}$, and extension at $72{ }^{\circ} \mathrm{C}$ for 50 s; and a terminal extension at $72{ }^{\circ} \mathrm{C}$ for 10 min. Each PCR product was purified using the QIAquick PCR Purification Kit (Qiagen, MD, USA), and sequenced by the Sangon Biotech Co., Ltd. (Shanghai, China). The amino acid sequences were analyzed by DNAMAN software (version 6.0; Lynnon Biosoft Bioinformatic Solutions). PCR amplifications were performed three times for each isolate to avoid sequence mismatches during PCR amplification and sequencing.

\section{Determination of the gene expression level of AaHK1}

To analyze the relative gene expression level of AaHK1 in A. alternata isolates, mycelial plugs were incubated in flasks containing PDB, with six replicate flasks for each isolate. After 2 days of incubation at $25^{\circ} \mathrm{C}$ in a shaker, three flasks were treated with $10 \mu \mathrm{g} / \mathrm{mL}$ of procymidone, and the other three were added with the same volume of sterile water and used as controls. After $12 \mathrm{~h}$, the mycelia of each isolate were harvested for RNA extraction using Total RNA Isolation kit (Promega, USA). Further, cDNA was synthesized using PrimeScript RT reagent kit with gDNA Eraser (TaKaRa, Japan). Primers used for quantitative PCR (qPCR) are shown in Table 6. qPCR was performed in an ABI 7500 Real-Time Detection System (Applied Biosystems) using SYBR Green I fluorescent dye detection. Amplification was performed in a $20-\mu \mathrm{L}$ volume containing $10 \mu \mathrm{L}$ of iTaq Universal SYBR Green Supermix (Bio-Rad Laboratories), $1 \mu \mathrm{L}$ of each of the forward and reverse primers $(10 \mu \mathrm{M}), 0.4 \mu \mathrm{L}$ of $50 \times$ ROX Reference Dye 2, $1 \mu \mathrm{L}$ of reverse transcription product, and $6.6 \mu \mathrm{L}$ of $\mathrm{ddH}_{2} \mathrm{O}$. The expression of AaHK1 was normalized to that of $\beta$-tubulin gene. The transcription level of $A a H K 1$ in each isolate relative to that of $\beta$-tubulin gene was calculated using the $2^{-\Delta \Delta \mathrm{Ct}}$ method (Wei et al. 2019). The experiment was repeated three times.

\section{Statistical analysis}

The SIGMA-STAT Statistical Software Package (SPSS Science, version 11) was used to analyze the data. Fisher's protected least significant difference $(P=0.05)$ test was calculated to evaluate statistical significance.

\section{Abbreviations}

ALSB: Alternaria leaf spots and blights; DMls: Sterol demethylation inhibitors; DCFs: Dicarboximide fungicides; DDK: C-terminus receiver domain harboring a three amino-acid signature; EC $_{50}$ : Effective concentration for 50\% mycelial inhibitive growth; HAMPs: Histidine kinases-Adenylate cyclases-Methyl accepting proteins and Phōsphatases; HATPāse_c: Cognate histidine kinaselike ATPase catalytic sub̄omains; HisKA: Histidine kinase A; HK: Histidine 
kinase; MAPK: Mitogen-activated protein kinase; MIGAs: Mycelial intracellular glycerol accumulations; Pro ${ }^{H R}$ : High-level procymidone-resistant; Pro ${ }^{L R}$ : Lowlevel procymidone-resistant; Pro ${ }^{M R}$ : Moderate-level procymidone-resistant; Pro $^{\mathrm{R}}$ : Procymidone-resistant; Pro ${ }^{\mathrm{S}}$ : Procymidone-sensitive; Qols: Quinoloxidizing inhibitors; RH: Relative humidity; SDHls: Succinate dehydrogenase inhibitors; MIC: Minimum inhibitory concentration

\section{Acknowledgements}

Not applicable.

\section{Authors' contributions}

BRW, TCL, LLW and WCC conducted the experiments. All authors analyzed the data. BRW, TCL and CCJ wrote and revised the manuscript. All authors read and approved the final manuscript.

\section{Funding}

This work was supported by National Science Foundation of China (No.31801778 \& No.31672065), Chinese Key R \& D Plan (2018YFD0201201, 2016YED0201007 \& 2018YFD0201000), Agricultural Science and Technology Projects of Jiangsu Province, China \{PZCZ201715, CX [19]3003, BE2018378, BA2018039, \& CX (18)2005\}.

\section{Availability of data and materials}

$$
\text { Not applicable. }
$$

\section{Declarations}

\section{Ethics approval and consent to participate}

Not applicable.

\section{Consent for publication}

Not applicable.

\section{Competing interests}

The authors declare that they have no competing interests.

\section{Author details}

'College of Plant Protection, Nanjing Agricultural University, Key Laboratory of Pesticide, Nanjing 210095, Jiangsu Province, China. ${ }^{2}$ Plant Protection and Quarantine Station of Xiangshui County|, Xiangshui 224600, Jiangsu Province, China. ${ }^{3}$ Agricultural Product Quality Safety Supervision and Management Station of Xiangshui County, Xiangshui 224600, Jiangsu Province, China. ${ }^{4}$ Jiangsu Coastal Area Institute of Agricultural Sciences, Yancheng 224002, Jiangsu Province, China.

Received: 17 January 2021 Accepted: 1 July 2021

Published online: 20 July 2021

\section{References}

Alberoni G, Collina M, Lanen C, Leroux P, Brunelli A. Field strains of Stemphylium vesicarium with a resistance to dicarboximide fungicides correlated with changes in a two-component histidine kinase. Eur J of Plant Pathol. 2010; 128(2):171-84. https://doi.org/10.1007/s10658-010-9642-9.

Avenot H, Simoneau P, lacomivasilescu B, Bataillesimoneau N. Characterization of mutations in the two-component histidine kinase gene AbNIK1 from Alternaria brassicicola that confer high dicarboximide and phenylpyrrole resistance. Curr Genet. 2005;47(4):234-43. https://doi.org/10.1007/s00294-0050568-2.

Avenot HF, Michailides TJ. Resistance to boscalid fungicide in Alternaria alternata isolates from pistachio in California. Plant Dis. 2007;91(10):1345-50. https:// doi.org/10.1094/PDIS-91-10-1345.

Avenot HF, Solorio C, Morgan DP, Michailides TJ. Sensitivity and cross-resistance patterns to demethylation-inhibiting fungicides in California populations of Alternaria alternata pathogenic on pistachio. Crop Prot. 2016;88:72-8. https:// doi.org/10.1016/j.cropro.2016.05.012

Brewster J, Valoir TD, Dwyer N, Winter E, Gustin M. An osmosensing signal transduction pathway in yeast. Science. 1993;259(5102):1760-3. https://doi. org/10.1126/science.7681220.

Cui W, Beever RE, Parkes SL, Templeton MD. Evolution of an osmosensing histidine kinase in field strains of Botryotinia fuckeliana (Botrytis cinerea) in response to dicarboximide fungicide usage. Phytopathology. 2004;94(10): 1129-35. https://doi.org/10.1094/PHYTO.2004.94.10.1129.

Cui W, Beever RE, Parkes SL, Weeds PL, Templeton MD. An osmosensing histidine kinase mediates dicarboximide fungicide resistance in Botryotinia fuckeliana (Botrytis cinerea). Fungal Genet Biol. 2002;36(3):187-98. https://doi.org/10.101 6/S1087-1845(02)00009-9.

Dry IB, Yuan KH, Hutton DG. Dicarboximide resistance in field isolates of Alternaria alternata is mediated by a mutation in a two-component histidine kinase gene. Fungal Genet Biol. 2004;41(1):102-8. https://doi.org/10.1016/j. fgb.2003.09.002.

Duan Y, Ge C, Liu S, Chen C, Zhou M. Effect of phenylpyrrole fungicide fludioxonil on morphological and physiological characteristics of Sclerotinia sclerotiorum. Pest Biochem Physiol. 2013;106(1-2):61-7. https://doi.org/10.101 6/j.pestbp.2013.04.004.

Fraile A, Alonso A, Sagasta EM. Some characteristics of Botrytis cinerea isolates tolerant to procymidone. Plant Pathol. 1986;35(1):82-5. https://doi.org/1 0.1111/j.1365-3059.1986.tb01984.x.

Fujimura M, Ochiai N, Ichiishi A, Usami R, Horikoshi K, Yamaguchi I. Fungicide resistance and osmotic stress sensitivity in os mutants of Neurospora crassa. Pest Biochem Physiol. 2000;67(2):125-33. https://doi.org/10.1006/pest.2000.24 79.

Grabke A, Fernandezortuno D, Amiri A, Li X, Peres NA, Smith P, et al. Characterization of iprodione resistance in Botrytis cinerea from strawberry and blackberry. Phytopathology. 2014;104(4):396-402. https://doi.org/10.1 094/PHYTO-06-13-0156-R

Guillemette T, lacomivasilescu B, Simoneau P. Conventional and real-time PCRbased assay for detecting pathogenic Alternaria brassicae in cruciferous seed. Plant Dis. 2004:88(5):490-6. https://doi.org/10.1094/PDIS.2004.88.5.490.

Han X, Zhao H, Ren W, Lv C, Chen C. Resistance risk assessment for fludioxonil in Bipolaris maydis. Pest Biochem Physiol. 2017;139:32-9.

Herivaux A, So YS, Gastebois A, Latge JP, Bouchara J, Bahn Y, et al. Major sensing proteins in pathogenic fungi: the hybrid histidine kinase family. PLoS Pathog. 2016;12(7):e1005683. https://doi.org/10.1371/journal.ppat.1005683.

Kuang J, Hou Y, Wang J, Zhou M. Sensitivity of Sclerotinia sclerotiorum to fludioxonil: in vitro determination of baseline sensitivity and resistance risk. Crop Prot. 2011:30(7):876-82. https://doi.org/10.1016/j.cropro.2011.02.029.

Li HX, Xiao CL. Characterization of fludioxonil-resistant and pyrimethanil-resistant phenotypes of Penicillium expansum from apple. Phytopathology. 2008;98(4): 427-35. https://doi.org/10.1094/PHYTO-98-4-0427.

Lin C, Chung K. Specialized and shared functions of the histidine kinase- and HOG1 MAP kinase mediated signaling pathways in Alternaria alternata, a filamentous fungal pathogen of citrus. Fungal Genet Biol. 2010;47(10):818-27. https://doi.org/10.1016/j.fgb.2010.06.009.

Luo Y, Yang J, Zhu M, Yan J, Mo M, Zhang K. Characterization of mutations in AlHK1 gene from Alternaria longipes: implication of limited function of twocomponent histidine kinase on conferring dicarboximide resistance. J Microbiol Biotechnol. 2008;18(1):15-22.

Luo Y, Yang J, Zhu ML, Liu CJ, Li HY, Lu Z, et al. The group III two-component histidine kinase AlHK1 is involved in fungicides resistance, osmosensitivity, spore production and impacts negatively pathogenicity in Alternaria longipes. Curr Microbiol. 2012;64(5):449-56. https://doi.org/10.1007/s00284-012-0093-8.

Ma H, Chen Y, Wang J, Yu W, Tang Z, Chen C, et al. Activity of carbendazim, dimethachlon, iprodione, procymidone and boscalid against Sclerotinia stem rot in Jiangsu Province of China. Phytoparasitica. 2009;37(5):421-9. https:// doi.org/10.1007/s12600-009-0057-0.

Ma Z, Felts D, Michailides TJ. Resistance to azoxystrobin in Alternaria isolates from pistachio in California. Pest Biochem Physiol. 2003;77(2):66-74. https://doi. org/10.1016/j.pestbp.2003.08.002.

Ma Z, Michailides TJ. Characterization of iprodione-resistant Alternaria isolates from pistachio in California. Pest Biochem Physiol. 2004;80(2):75-84. https:// doi.org/10.1016/j.pestbp.2004.06.007

Meena M, Samal S. Alternaria host-specific (HSTs) toxins: an overview of chemical characterization, target sites, regulation and their toxic effects. Toxicol Rep. 2019;6:745-58. https://doi.org/10.1016/j.toxrep.2019.06.021.

Miller TK, Renault S, Selitrennikoff CP. Molecular dissection of alleles of the osmotic-1 locus of Neurospora crassa. Fungal Genet Biol. 2002;35(2):147-55. https://doi.org/10.1006/fgbi.2001.1306.

Motoyama T, Kadokura K, Ohira T, Ichiishi A, Fujimura M, Yamaguchi I, et al. A two-component histidine kinase of the rice blast fungus is involved in osmotic stress response and fungicide action. Fungal Genet Biol. 2005;42(3): 200-12. https://doi.org/10.1016/j.fgb.2004.11.002. 
Mukesh M, Andleeb Z, Dubey MK, Mohd A, Gupta VK, Upadhyay RS. Comparative evaluation of biochemical changes in tomato (Lycopersicon esculentum Mill.) infected by Alternaria alternata and its toxic metabolites ( $(\mathrm{TeA}, \mathrm{AOH}$, and AME). Front Plant Sci. 2016;7(53):1408.

Nowicki M, Nowakowska M, Niezgoda A, Kozik EU. Alternaria black spot of crucifers: symptoms, importance of disease, and perspectives of resistance breeding. Veg Crops Res Bull. 2012;76(2012):5-19. https://doi.org/10.2478/v1 0032-012-0001-6.

Ochiai N, Fujimura M, Motoyama T, Ichiishi A, Usami R, Horikoshi K, et al. Characterization of mutations in the two-component histidine kinase gene that confer fludioxonil resistance and osmotic sensitivity in the os-1 mutants of Neurospora crassa. Pest Manag Sci. 2010;57(5):437-42.

Oshima M, Fujimura M, Banno S, Hashimoto C, Yamaguchi I. A point mutation in the two component histidine kinase BCOS-1 gene confers dicarboximide resistance in field isolates of Botrytis cinerea. Phytopathology. 2002:92(1):7580. https://doi.org/10.1094/PHYTO.2002.92.1.75.

Ren W, Shao W, Han X, Zhou M, Chen C. Molecular and biochemical characterization of laboratory and field mutants of Botrytis cinerea resistant to fludioxonil. Plant Dis. 2016;100(7):1414-23. https://doi.org/10.1094/PDIS-11-1 5-1290-RE.

Sang C, Ren W, Wang J, Xu H, Zhang Z, Zhou M, et al. Detection and fitness comparison of target based highly fludioxonil-resistant isolates of Botrytis cinerea from strawberry and cucumber in China. Pest Biochem Physiol. 2018; 147:110-8. https://doi.org/10.1016/..pestbp.2018.01.012.

Steel CC. Catalase activity and sensitivity to the fungicides, iprodione and fludioxonil in Botrytis cinerea. Lett Appl Microbiol. 1996;22(5):335-8. https:// doi.org/10.1111/j.1472-765X.1996.tb01173.x.

Steel CC, Nair NG. Oxidative protective mechanisms and resistance to the dicarboximide fungicide, iprodione, in Alternaria alternata. J Phytopathol. 1995;143(9):531-5. https://doi.org/10.1111/j.1439-0434.1995.tb00658.x.

Surviliene E, Dambrauskiene E. Effect of different active ingredients of fungicides on Alternaria spp. growth in vitro. Agron Res. 2006;4:403-6.

Wei L, Chen W, Zhao W, Wang J, Wang B, et al. Mutations and overexpression of CYP51 associated with DMI-resistance in Colletotrichum gloeosporioides from Chili. Plant Dis. 2019;104(3):668-76.

Woudenberg JHC, Seidl MF, Groenewald JZ, De Vries M, Stielow JB, Thomma $\mathrm{BPHJ}$, et al. Alternaria section Alternaria: species, formae speciales or pathotypes? Stud Mycol. 2015;82:1-21. https://doi.org/10.1016/j.simyco.2015. 07.001.

Wu D, Zhang R, Han X, Wang J, Zhou M, Chen C. Resistance risk assessment for fludioxonil in Stemphylium solani. Ann Appl Biol. 2015;167(2):277-84.

Yoshimi A, Imanishi J, Gafur A, Tanaka C, Tsuda M. Characterization and genetic analysis of laboratory mutants of Cochliobolus heterostrophus resistant to dicarboximide and phenylpyrrole fungicides. J Gen Plant Pathol. 2003;69(2): 101-8. https://doi.org/10.1007/s10327-002-0004-0.

Yoshimi A, Tsuda M, Tanaka C. Cloning and characterization of the histidine kinase gene Dic1 from Cochliobolus heterostrophus that confers dicarboximide resistance and osmotic adaptation. Mol Gen Genomics. 2004; 271(2):228-36. https://doi.org/10.1007/s00438-003-0974-4.

Zhang Z, Ren W, Wang J, Chen W, Sang C, Chen C. Resistance risk assessment of Fusarium oxysporum $\mathrm{f}$. sp. melonis against phenamacril, a myosin inhibitor. Pest Biochem Physiol. 2017;147:127-32.

Ready to submit your research? Choose BMC and benefit from:

- fast, convenient online submission

- thorough peer review by experienced researchers in your field

- rapid publication on acceptance

- support for research data, including large and complex data types

- gold Open Access which fosters wider collaboration and increased citations

- maximum visibility for your research: over $100 \mathrm{M}$ website views per year

At $\mathrm{BMC}$, research is always in progress.

Learn more biomedcentral.com/submissions 